\title{
CORRECTION
}

\section{Correction to: Long-term almond yield response to deficit irrigation}

\author{
David Moldero $^{1}\left[\right.$ - Álvaro López-Bernal ${ }^{2} \cdot$ Luca Testi $^{1} \cdot$ Ignacio Jesús Lorite $^{3} \cdot$ Elías Fereres $^{1,2} \cdot$ Francisco Orgaz $^{1}$
}

Published online: 28 April 2021

(c) Springer-Verlag GmbH Germany, part of Springer Nature 2021

\section{Correction to: Irrigation Science}

https://doi.org/10.1007/s00271-021-00720-8

The published article has a typographic error on the label of the equation that appears in Fig. 4a, where it appears as $Y_{\mathrm{DW}}=-0.0023 \mathrm{IR}^{2}+5.5499 \mathrm{IR}+454.92$ when the corrected equation is $Y_{\mathrm{DW}}=-0.0023 \mathrm{IR}^{2}+4.5499 \mathrm{IR}+454.92$.

This is a typing error generated in the transcription of the equation during the graphic work and in no way alters the results presented in the graphs. The published paper has been carefully checked, and we have verified that the equation drawn in the published Fig. 4 a was made with the correct equation, as is the case with the derivate of the equation that appears published in Fig. 5 [IWMP $=(-0.0046$ $\mathrm{IR}+4.5499) / 10]$.

The original article can be found online at https://doi.org/10.1007/ s00271-021-00720-8.

David Moldero

dmoldero@ias.csic.es

1 Department of Agronomy, IAS-CSIC, Córdoba, Spain

2 Department of Agronomy, University of Córdoba, Córdoba, Spain

3 Deparment of Agriculture and Environment, IFAPA, Córdoba, Spain
Publisher's Note Springer Nature remains neutral with regard to jurisdictional claims in published maps and institutional affiliations. 